\title{
Political Diversity and Participation: A Systematic Review of the Measurement and Relationship ${ }^{1}$
}

\author{
Najin Jun \\ Hannam University
}

\begin{abstract}
This study reviews existing research on the measurement of and the relationship between political diversity and political participation. It addresses the inconsistency in the arguments of existing studies researching the influence of political diversity on political participation. It attempts to find the cause in the variety of approaches to conceptualize and operationalize the two variables. As the measure of political diversity, political network heterogeneity and network attributes are discussed in detail in specific relation to political participation. As for political participation, an in-depth analysis of various ways to understand different forms of political involvement is presented. Implications for public opinion research are discussed.
\end{abstract}

Keywords: political diversity, political participation, political network heterogeneity, political discussion network, network attributes

1 This research was supported by 2012 Hannam University Academic Research Grant. I thank Hannam University for the grant. 


\section{Introduction}

Political diversity and political participation are two elements central to a healthy democracy. Political diversity facilitates the exchange of heterogeneous ideas, which in turn fosters deliberative democracy. Through political participation, citizens wield their power to make collective political decisions that will affect their own lives. A higher level of political participation in society leads to participatory democracy. As political diversity and participation support the two different (though not necessarily mutually exclusive) forms of democracy, scholars have researched how diversity might influence participation with the main discussion revolving around the issue of compatibility between deliberative democracy and participatory democracy.

Some studies found that political diversity has demobilizing consequences for political participation (e.g., Grober \& Schram, 2006; McClurg, 2006a, 2006b; Mutz, 2002, 2006; Ulbig \& Funk, 1999), while others showed that diversity actually helps facilitate higher participation (e.g., Huckfeldt, Johnson \& Sprague, 2002, 2004; Jang, 2009; Leighley, 1990, McLeod, Kosicki, \& McLeod, 1994; Scheufele, Nisbet, Brossard \& Nisbet, 2004). The discrepancy and inconsistency in the findings of the research might be a result of different theoretical frameworks employed in the studies. Yet, what is noticed is that the measurement of diversity and participation differs significantly from one study to another. For example, political diversity is often measured by the level of exposure to non-likeminded political information in one's social network. Studies employed a wide variety of ways to define what the "non-likeminded" information is and to generate individuals' social networks. For political participation, existing studies differ greatly in the number and types of political activities they count as a "participatory act." This inconsistency in the measurement of political diversity and participation has an implication for public opinion research. It can blur the definition of political diversity and participation in the research on people's political involvement. Further, it may also hamper people's perception and understanding of political difference and engagement unless a corrective measure is introduced. Therefore, the issue of the measurement of political diversity and participation warrants much further attention.

Focusing on the conceptualization and operationalization of political diversity and political participation, this study reviews existing research on the measurement of and 
the relationship between the two variables. It first examines the many different ways political diversity has been conceptualized and discusses the various ways the attributes of social networks have been treated with a focus on possible ways in which they could have affected the results of the studies. Finally, it analyzes political participation as studied by existing research.

\section{Political Diversity}

Political diversity is generally understood as the extent to which one is exposed to political ideas that are different from her own. Methodologically, in examining the level of political diversity, some studies rely on the pattern of individual media consumption practice. For example, Stroud (2007) looked at consumption of certain political websites to measure partisan media use. Garret (2009) examined time spent reading issue-related online news. Examining individual media consumption practices has merits in that it informs the ways in which people expose themselves to some types of information and not others on the media. However, while it looks at political diversity rather as a narrowly defined concept. People can expose themselves to both congenial and contradicting messages through not only media but also face-to-face interactions. Examining online news consumption or discussions does not predict face-to-face exchange of information because the two forms of communication differ considerably: while face-to-face discussion is mostly oral and synchronous, online discussion can be oral or written, synchronous or asynchronous (Lin, 2001). Some studies even predicted that that online communication could be more goal-oriented, hence more efficient and mobilizing than offline discussion (Berger, 2009).

One attempt to incorporate face-to-face political discussions into the examination of political diversity is Brundidge's (2010) study. It demonstrates the process of inadvertency by examining the extent to which online news use is related to people's political diversity through discussion online and at their workplace, where unanticipated exposure to dissonant views is likely to take place. Measured by the frequency of political discussion with others whose political and social characteristics differ from the individual, political network heterogeneity has been a useful way to assess the level of exposure to political differences or political diversity. In fact, in existing research, political 
diversity in face-to-face social relations is examined often by political network heterogeneity.

Political diversity has been considered one of the most important attributes of face-to-face political discussion networks in much of the research on the relationship between political difference and political participation (e.g., Eveland \& Hively, 2005; Mutz, 2002, 2006; Huckfeldt, Johnson, et al., 2002, 2004; Jang, 2009; Kwak, Williams, Wang, \& Lee, 2005; McLeod et al., 1994; Scheufele, Hardy, Brosard, Waismel-Manor \& Nisbet, 2006; Scheufele et al., 2004). The ways in which research sees how political difference affects people's political participation decisions vary. On one hand, exposure to political difference has been found to be negatively related to political participation (Grober \& Schram, 2006; McClurg, 2006a, 2006b; Mutz, 2002, 2006; Ulbig \& Funk, 1999) as it increases cross-pressure and ambivalence (Berelson, Lazarsfeld \& McPhee, 1954; Lazarsfeld, Berelson, \& Gaudet, 1944) especially for those who are conflict-avoidant (Mutz, 2006) and in political minority status (McClurg, 2006a). On the other hand, exposure to political difference has also been found to contribute to an increased level of participation (Huckfeldt, Johnson, \& Sprague, 2004, 2006; Jang, 2009; Leighley, 1990, McLeod et al, 1994; Scheufele, et al., 2004). This inconsistency in findings stems in large part from the different approaches in the conceptualization and operationalization of political network heterogeneity to present exposure to political difference in different studies (Eveland \& Hively, 2005). As will be discussed later, how the term is conceptualized has a considerable consequence for the outcome of the study (for instance, see Huckfeldt, Johnson, et al., 2004 and Mutz, 2006).

In current research, political network heterogeneity has been conceptualized and operationalized in at least five non-exclusive sets of ways. Each set consists of competing approaches: first, political heterogeneity is measured in terms of disagreement (e.g., Mutz, 2006) or in terms of a combination of socio-demographic and some attitudinal characteristics (e.g., Scheufele et al., 2006); second, diversity is seen from inside the network to compare differences between an individual and each of the discussion partners in the network (e.g., Kwak et al., 2005) or from outside the network to capture differences among all members of the network (e.g., Huckfeldt, Johnson, et al., 2004); third, heterogeneity is defined as strictly and directly opposing viewpoints (e.g., Mutz, 2002a) or as a lack of agreement (e.g., Huckfeldt, Mendez \& Osborn, 2004); fourth, 
heterogeneity is captured from a given number of identified discussion partners as a network (e.g., Jang, 2009) or from an indefinite number of unspecified discussion partners (e.g., Scheufele et al., 2004); and fifth, heterogeneity is conceptualized as the number of dissimilar people in a network (e.g., Jang, 2009), or the frequency of political discussions between an individual and dissimilar people (e.g., Scheufele et al., 2006), or the extent to which discussants disagree with each other (e.g., Mutz, 2002a).

\section{Competing Concepts of Political Network Heterogeneity}

The five sets of competing approaches to conceptualization and operationalization of political network heterogeneity identified above can be summarized as: 1) difference in socio-demographic characteristics vs. disagreement; 2) "different from me" vs. "different from one another;" 3) opposing viewpoints vs. lack of agreement; 4) a limited number of discussion partners vs. an indefinite number of discussion partners; and 5) size vs. frequency vs. degree of difference.

Traditionally, the differences in socio-demographic characteristics are more emphasized in the sociological approach (McPherson, Smith-Lovin, \& Cook, 2001), while disagreement (diversity in political opinions) tends to be given more emphasis in the realm of political science, particularly in election studies (e.g., Huckfeldt, Johnson et al., 2002, 2004; Jang, 2009; Mutz, 2002, 2006). Some researchers take into account both aspects (e.g., Brundidge, 2010; Kwak et al., 2005; McLeod et al., 1994; Scheufele, et al., 2006).

The second difference is in the vantage point from which heterogeneity is observed. Network heterogeneity can be seen from the inside of the network, i.e., difference between oneself and each of all others in the network, or from the outside of the network, i.e., difference among all members in the network. While assumed by a limited number of researchers, the latter position (Huckfeldt, Johnson et al., 2002; Huckfeldt, Mendez et al., 2004) leads to the investigation of how people and their voting decisions are influenced by others' opinions, particularly majority ones. Thirdly, disagreement is defined as exposure to opinions that are opposing one's own perspectives (Mutz, 2006) and also seen as a lack of agreement (Huckfeldt, Johnson et al., 
2004). This difference in the conceptualization contributes to a significant discrepancy in the measurement of disagreement because, for instance, a neutral position would constitute disagreement for one who is taking a particular side in the case of the latter, but not in the case of the former since being neutral is not exactly an opposing viewpoint of any specific position.

The fourth difference lies in the way a discussion network is generated. While many of the studies elicit three to four primary discussion partners from an individual and examine their characteristics (e.g., Huckfeldt, Johnson et al., 2002, 2004; Jang, 2009; Mutz, 2002), some studies (e.g., Brundidge, 2010; Kwak et al., 2005; Scheufele, et al.,2006) depend on the frequency of discussion with an indefinite number of people who are dissimilar from oneself. Inherently, the frequency of discussion is embedded in the generation of the discussion network in the latter case whereas the same can be treated separately in the former case. The fifth discrepancy is in the term by which the levels of political difference are measured. Some studies measure difference by the number of dissimilar partners in the network, i.e., size, (e.g., Jang, 2009) while some others measure the frequency of discussion with dissimilar partners, i.e., frequency, (e.g., Scheufele et al, 2006). More contextually, other studies measure the degree of difference (e.g., Mutz, 2002a). In combination with different ways of treating network size and discussion frequency in analysis as will be discussed later, these diverse methods of conceptualization and operationalization of political network heterogeneity (Eveland \& Hively, 2005) seem to have contributed to a general lack of consistency in findings and, in some cases, a bias in certain directions.

The competing concepts of political network heterogeneity are summarized and presented in Table 1. 
Table 1

Competing Concepts of Political Network Heterogeneity

\begin{tabular}{|c|c|c|}
\hline $\begin{array}{l}\text { Competing } \\
\text { Concepts }\end{array}$ & Description & $\begin{array}{l}\text { Example Studies \& } \\
\text { Findings (relation to } \\
\text { political participation) }\end{array}$ \\
\hline $\begin{array}{l}\text { Socio-demographic } \\
\text { \& Attitudinal } \\
\text { Characteristics }\end{array}$ & $\begin{array}{l}\text { Dissimilarity in socio-demographic } \\
\text { attributes and political views }\end{array}$ & $\begin{array}{l}\text { McLeod et al. (1994) + } \\
\text { Kwak et al. }(2005)+ \\
\text { Scheufele et al. }(2006)+\end{array}$ \\
\hline $\begin{array}{l}\text { vs. } \\
\text { Disagreement }\end{array}$ & Dissimilarity in political views & $\begin{array}{l}\text { Huckfeldt, Johnson et al. } \\
(2002,2004)+ \\
\text { Mutz }(2002 a, 2006)-\end{array}$ \\
\hline $\begin{array}{l}\text { Dissimilarity } \\
\text { between }\end{array}$ & Dissimilarity from the ego & $\begin{array}{l}\text { Leighley }(1990)+ \\
\text { Mutz }(2002 \mathrm{a}, 2006)\end{array}$ \\
\hline $\begin{array}{l}\text { Discussants } \\
\quad \text { vs. } \\
\text { Dissimilarity } \\
\text { among Discussants }\end{array}$ & Dissimilarity in the network & $\begin{array}{l}\text { Huckfeldt, Johnson et al. } \\
(2002,2004)+ \\
\text { Nir }(2005) \text { network } \\
\text { ambivalence + }\end{array}$ \\
\hline $\begin{array}{l}\text { Opposing } \\
\text { Viewpoints } \\
\quad \text { vs. }\end{array}$ & $\begin{array}{l}\text { Viewpoint in direct opposite from } \\
\text { the ego's (e.g., Republican vs. } \\
\text { Democrat) }\end{array}$ & Mutz (2002a, 2006) - \\
\hline Lack of Agreement & $\begin{array}{l}\text { Viewpoint different from the ego's } \\
\text { (e.g., Republican vs. Democrat vs. } \\
\text { Independent) }\end{array}$ & $\begin{array}{l}\text { Huckfeldt, Johnson et al. } \\
(2002,2004)+\end{array}$ \\
\hline $\begin{array}{l}\text { Limited \# of } \\
\text { Discussants }\end{array}$ & $\begin{array}{l}\text { Network generated by eliciting } 3 \\
\text { to } 5 \text { identified discussants }\end{array}$ & $\begin{array}{l}\text { Leighley }(1990)+ \\
\text { McClurg }(2006 \mathrm{~b})-\end{array}$ \\
\hline $\begin{array}{l}\quad \text { vs. } \\
\text { Indefinite \# of } \\
\text { Discussants }\end{array}$ & $\begin{array}{l}\text { Network generated by the } \\
\text { frequency of discussion with an } \\
\text { unlimited \# of unspecified } \\
\text { dissimilar discussants }\end{array}$ & $\begin{array}{l}\text { Kwak et al. }(2005)+ \\
\text { Scheufele et al. }(2006)+\end{array}$ \\
\hline $\begin{array}{l}\text { Size } \\
\text { vs. }\end{array}$ & $\begin{array}{l}\text { Number of dissimilar discussants } \\
\text { in the network }\end{array}$ & Jang (2009) -, + \\
\hline $\begin{array}{l}\text { Frequency } \\
\text { vs. }\end{array}$ & $\begin{array}{l}\text { Frequency of discussion with } \\
\text { dissimilar partners }\end{array}$ & Scheufele et al. (2006) + \\
\hline $\begin{array}{l}\text { Degree of } \\
\text { Difference }\end{array}$ & $\begin{array}{l}\text { Extent of disagreement with a } \\
\text { partner weighted by discussion } \\
\text { frequency }\end{array}$ & Mutz (2002a, 2006) - \\
\hline
\end{tabular}




\section{Attributes of Political Discussion Networks}

All the approaches to measuring political diversity discussed thus far rely on political discussion networks. Indeed, a vast body of literature focuses on discussion networks as a facet of social context in relation to the extent of individual political involvement (McLeod et al., 1994). Essentially, they examine the characteristics or attributes of discussion networks.. Among the characteristics to describe a discussion network, network size (how large the network is), discussion frequency (how often the individual discusses politics with people in his network), and tie strengths (how close the individual's relations to the discussion partners are) are three most researched attributes (Kwak et al., 2005). How these three attributes are treated and controlled may alone explain the vast difference in the conclusions of the existing research on the relationship between heterogeneity and participation (Eveland \& Hively, 2009). For example, Mutz (2002a) shows a negative influence of heterogeneity with the controls of network size and discussion frequency, whereas Kwak et al. (2005) find a positive impact without controlling for network size and discussion frequency. Although less studied than the other two network attributes, tie strengths is also an attribute that has been studied as affecting participatory outcomes. For instance, Schmitt-Beck (2004) observed that different depths of relationship have different influences on political participation.

This section reviews different approaches to understand and operationalize network size, discussion frequency and tie strengths in the existing studies in specific reference to their implications on political diversity and political participation.

\section{Network Size}

It has been generally consistent in the existing research that the level of political participation increases as network size increases (Huckfeldt, Johnson et al., 2004; Jang, 2009; Kwak et al., 2005; Leighley, 1990; McLeod et al., 1994; Moy \& Gastil, 2006; Mutz, 2002). Larger social networks increase the opportunities to encounter politically active individuals and, thus, increase the likelihood of participation (Leighley, 1990). Alternatively, they are likely to contribute to participation as they stimulate greater discussion frequency and enhance political knowledge (Eveland \& Hively, 2005). 
Kwak et al. (2005) found that individuals tend to be more participatory when discussing politics with likeminded people in the case of a small network. Conversely, in the case of a large network, people discussing politics with likeminded people tend to be less participatory.

When it comes to the operationalization of network size, approaches in the literature vary. At least three different approaches are noticed. First, some studies elicit only three to five clearly identified discussion partners due to time constraints researchers have (e.g., Mutz, 2002). Inherently, this approach limits the size of the network to three to five. Because this approach focuses on the small network of three to five clearly identified people, it can accurately measure the difference in opinions and characteristics of discussants or how the difference affects the individual in forming his own opinion. The issue that arises with this "artificially constrained" network size is that it tends to over-represent the primary discussion partners and suppress the "marginals," who might be infrequent discussion partners but convey contrary information into the network (Eveland \& Hively, 2005). This approach may suffer from selection bias. Additionally, the method seems to be limited in reflecting the contemporary communication environment, which includes not just three to five partners but any number of partners one communicates with face-to-face as well as through media.

Second, some studies directly ask respondents about the total number of discussion partners (Kwak et al., 2005). While an unlimited network size could be obtained this way, the identities of the discussion partners are undisclosed, which makes the measurement less useful when the relationship between discussants needs to be examined. Another issue is that this method of operationalization is biased toward discussion frequency as it asks how often the respondent has political talks with dissimilar partners in the process of network generation. Although the general discussion frequency can be controlled for, the effect of discussion frequency with dissimilar partners based on the given set of characteristics (e.g., political views, ideology, race) would not be totally suppressed when necessary.

Third, another set of studies does not attend to network size at all (e.g., Scheufele et al., 2006). As in the second method, generation of networks is done by asking respondents how often they have political discussions with people with certain 
characteristics (e.g., conservative/liberal, women/men, white/black/Hispanic). Because their network generation is based on frequency, they share with the second method such issues as difficulty in assessing the relationship between discussants and the bias toward frequency.

\section{Discussion Frequency}

As in the case of network size, discussion frequency has also been consistently found to be positively related to participation (Kwak et al., 2005; Leighley, 1990; Mutz, 2002, 2006; Scheufele et al., 2006). Frequent discussion often leads to a "more informed and participative citizenry" when compared to lower engagement in political discussions (Eveland \& Hively, 2005, p. 209). Some observers have also seen that the positive association between discussion frequency and participation is channeled through increased political knowledge, news media use (McLeod et al., 1994) and interpersonal communication (Verba, Scholzman \& Brady, 1995). Discussion frequency was also found to moderate the effect of network heterogeneity. Kwak et al. (2005) found that higher frequency was positively related to participation regardless of the level of heterogeneity, but the relationship was significantly stronger for those whose network was more heterogeneous. The existing studies operationalized discussion frequency primarily in two ways.

First, some ask how often the respondent has political discussions with each partner specified in the process of network generation (e.g., Jang, 2009). This approach is useful for examining different dimensions of the network because it can be treated separately from other attributes of the network such as size and diversity.

Second, as mentioned in the discussion of network size, some other researchers ask how often a respondent discusses politics with dissimilar partners (e.g., Scheufele et al., 2006). In comparison to the first approach, this method seems to have two weaknesses: first, there is no way of assessing how often the respondent discusses politics with likeminded discussion partners; secondly, there is no way of controlling multiple conversations with the same person because discussion partners are undisclosed. One of the implications of these weaknesses on examining the relationship 
between network heterogeneity and political participation could be that the effect of frequency and the effect of diversity could potentially be confounded in favor of a positive association because measures of the two attributes cannot be treated separately. The general positive effect of frequency may override any influence of diversity on participation unless a careful arrangement is made to overcome this issue.

\section{Tie Strengths.}

Tie strengths is a relatively less researched dimension of discussion networks. Research has shown that different depths of relationships have different effects on political diversity (Jun, 2012) and political participation (Schmitt-Beck, 2004). Some of the earlier studies in political communication show that people in a close relationship exert a higher influence than acquaintances on political recruitment and participation (Katz \& Lazarsfeld, 1955). Discussions with close friends and family can be different from those with acquaintances, coworkers or distant friends in that the former can carry such characteristics as "intimacy, trust, respect, access and mutual regard" that are more likely to be absent in the latter (Kenny, 1994, p. 718). People generally feel closer to those who share their political values and they talk more frequently with those in close relationships (Huckfeldt \& Spague, 2005; Mutz \& Martin, 2001).

The motivation for examining this dimension of networks was furthered by the growing attention on weak ties spurred by the seminal study of Granovetter (1973). In addition, the proposition of structural holes (Burt, 1992) stimulated research to attend to how the individuals linking two separate dissimilar networks might influence members of the network differently than other individuals might. This dimension of networks is relevant for the study of the relationship between political diversity on participation, particularly in the sense that the "survival of disagreement" depends on the permeability of networks created by weak ties and structural holes (Huckfeldt, Johnson, et al., 2002). Indeed, it is the "marginals" or weak ties that serve as important sources of new, contrary and heterogeneous information (Weimann, 1982).

Contrary to earlier research that saw strong ties exerting higher influence (e.g., Katz and Lazarsfeld, 1995), Huckfeldt, Johnson, et al. (2002) argued that weak ties are at least as important as strong ties in politically influencing networks in that weak ties bring 
together individuals who hold politically divergent preference leading to higher participation. In the realm of civic engagement, Son and Lin (2008) found a positive association between the number of weak ties and civic engagement demonstrating that weak ties enhance the opportunities for recruitment.

More recently, Gil de Zúñiga and Valenzuela (2011) found a mediation effect of weak ties between network size and participation suggesting that larger networks have more weak ties, which in turn increase civic involvement. As such, some see close relationships as more important whereas others emphasize weak ties for positive participatory outcomes. Unlike the first two network attributes, therefore, there seems to be a lack of general agreement in research as to how tie strengths are related to participation.

\section{Political Participation}

The motivation of this study was to understand the various ways of measuring political diversity in relation to political participation in existing research and to investigate the ways in which they influenced the inconsistency in the outcome of the research. I have thus far examined different ways of conceptualizing and operationalizing political network heterogeneity as an instrument to measure political diversity. I discussed network size, discussion frequency and tie strengths of the network and the issues arising from different treatment of the network attributes in specific regard to the relation between political diversity and participation. With the analyses, I have demonstrated that the differing measures of political diversity could have resulted in the wide discrepancies in existing research on political diversity and its influence on participation.

By the same token, it appears to be reasonable to question how political participation itself was understood in existing literature. Indeed, investigating how exposure to political diversity influences the extent of individual political activities, many studies examine individual political participation with different approaches to understanding the term. 


\section{Forms of Political Participation}

In the area of election studies, studies tend to look at voting only (e.g., Huckfeldt, Johnson et al., 2002; Jang, 2009), whereas in other areas, research includes activities such as writing letters to editors and politicians, displaying yard signs, wearing stickers and buttons, participating in a political party or campaign, etc., in addition to voting (e.g., Scheufele et al., 2006). Some studies treat voting separately from other activities (e.g., Leighley, 1990; Mutz, 2002), while some other studies only look at other forms of participation and do not consider voting at all (e.g., Kwak et al., 2005; McLeod et al., 1994).

Nevertheless, voting is the fundamental form of individual political engagement and a vast body of literature in political participation began from voting and moved on to other forms of political activities that were considered distinct from voting. This is in part because traditional studies of models of political participation focused on individual attributes as determinants of individual political participatory behavior; such research viewed people as isolated individuals whose access to the "political arena" is basically a personal problem with an individual solution (Zipp \& Smith, 1979). Underlying this assumption is the social psychological perspective that the determinants of the extent of political engagement are individual attributes such as personal interests and beliefs (e.g., Campbell, Gurin \& Miller, 1954). ～Nevertheless, since Lazarsfeld et al. (1944) identified the role of recruitment in political participation through their opinion leader model, some studies began to broaden their attention from social psychological factors to social interactive aspects. Based on their opinion leader and two step flow model, Berelson et al. (1954) demonstrated the efficacy of interpersonal communication for individual participation. They found evidence that people who were contacted by party workers for recruitment are more likely to participate in political activities. As another example, with his concept of proximity to the "public arena," Orum (1976) proposed that external factors are at least as important as individual attributes in predicting individual political involvement. The research by Berelson et al. (1954) and Orum (1976) effectively demonstrated that individual attributes are not the sole determinants of the extent of individuals' political activities and that social interactive aspects need further attention.

Building on the concept of the "public arena" proposed by Orum (1976), Zipp and Smith (1979) examined the ways in which individual and external factors contribute to 
different forms of participation. They grouped forms of participation primarily into two categories: voting and extra-voting activities. Their findings indicated that voting and campaigning (extra-voting) activities are qualitatively different forms of activity and that individual attributes determine only voting behavior and not campaigning activities. In consonance with Berelson et al.'s (1954) evidence, they saw that campaign activities increased by $50 \%$ as a result of being recruited, in other words, through social interaction. This finding is significant particularly for the understanding of social networks and political participation because it suggests that interaction through social networks may influence some political activities and not others. The categorization of voting and extra-voting is conceptually more refined by Huckfeldt (1979). In his examination of the contribution of neighborhood social context to political participation, Huckfeldt (1979) groups a number of political activities into two categories based on the context in which the act is carried out. Individually-based participation is acts that are performed in isolation, such as voting and writing letters to political leaders or editors of newspapers. Socially-based participation includes acts that are conducted in public or with knowledge of other people, which often involve social interaction such as recruitment and solicitation. Examples for socially-based participation are joining and participating in a political party and campaign, donating, and working to get people registered to vote. His conclusion is that contextual characteristics influence sociallybased, but not individually-based, forms of participation. This conclusion was successfully replicated by Giles and Dantico (1982).

However, the distinction between the two groups is not clear cut. For example, Huckfeldt (1979) assumes that all acts of donating money are solicited, i.e., people donate money only when they are asked. However, people can donate out of self motivation or as a reaction to an advertisement, which do not necessarily involve social interaction. In this case, donating money may be more of individually-based than socially-based (Leighley, 1990). In this regard, the research by Leighley (1990) adds a more sophisticated attempt to the literature to classify forms of participation. Her perspective rests on the resources or information an individual must have to engage in a particular political activity, whereas Huckfeldt's individually-and-socially-based model attends to the location in which the political act is performed. She assumes that certain political acts such as campaign activities require a higher level of information whereas voting needs 
information that is relatively easily available. Based on the level of information required, she orders actions from low to high voting, contacting, campaigning and cooperative activities. What is more meaningful in her study is the contrast of her findings from other research. She finds that "discussant conflict" or political heterogeneity affects not only individually-based political acts (voting) but also socially-based behaviors (contacting and campaigning).

McLeod et al. (1994) also add to the understanding of different criteria of political participation with their investigation of network heterogeneity and public forum participation. They see forms of participation as traditional and nontraditional, where the former represents such acts as voting and donating money and the latter includes such behavior as taking part in a deliberative forum. Although there is an inherent overrepresentation of white, high-status males in deliberative fora, they assert that deliberative participation is a "problem-solving" conversation that triggers intrapersonal reasoning at the micro level and social blending of diverse opinions at the macro level (McLeod et al., 1994, p. 744-745). Their finding of a positive influence of heterogeneity on public forum participation supports this assertion.

Another contribution to the forms of participation comes from Mutz $(2002,2006)$. She examines the effect of cross-cutting exposure on two sets of political activities: 1) confrontational acts include convincing other people to vote for/against certain candidates or working for a party or campaign; and 2) non-confrontational activities include attending meetings and rallies, donating money and wearing stickers and buttons. However, this distinction is not free from the grey area: participating in a rally may very well be a confrontational act as it could provoke a counteraction from groups assuming different positions. Her finding shows a disabling effect of cross-cutting exposure on confrontational participation and voting, which was treated separately.

A summary of different criteria for participatory forms discussed thus far is presented in Table 2 
Table 2

Forms of Political Participation

\begin{tabular}{|c|c|c|c|}
\hline Study & Categorization & Activities & $\begin{array}{l}\text { Relation with } \\
\text { Political } \\
\text { Diversity }\end{array}$ \\
\hline \multirow{2}{*}{$\begin{array}{l}\text { Zipp \& Smith } \\
\text { (1979) }\end{array}$} & Voting & Voting & 0 \\
\hline & Extra-voting & Campaigning & $\begin{array}{l}+ \text { (Social } \\
\text { Context) }\end{array}$ \\
\hline \multirow[t]{2}{*}{$\begin{array}{l}\text { Huckfeldt } \\
\text { (1979) }\end{array}$} & Individually-based & $\begin{array}{l}\text { Voting, sending protest } \\
\text { messages, making my views } \\
\text { known, writing letters to } \\
\text { editors }\end{array}$ & 0 \\
\hline & Socially-based & $\begin{array}{l}\text { Participating in a party, giving } \\
\text { money, getting people to vote, } \\
\text { campaigning, joining } \\
\text { community groups, informing } \\
\text { others about politics, } \\
\text { supporting a party }\end{array}$ & $\begin{array}{l}+ \text { (Social } \\
\text { Context) }\end{array}$ \\
\hline \multirow[t]{2}{*}{$\begin{array}{l}\text { Giles \& Dantico } \\
\text { (1982) }\end{array}$} & Individually-based & $\begin{array}{l}\text { Voting, sending protest } \\
\text { messages, making my views } \\
\text { known, writing letters to } \\
\text { editors }\end{array}$ & 0 \\
\hline & Socially-based & $\begin{array}{l}\text { Participating in a party, giving } \\
\text { money, getting people to vote, } \\
\text { campaigning, joining } \\
\text { community groups, informing } \\
\text { others about politics, } \\
\text { supporting a party }\end{array}$ & $\begin{array}{l}+ \text { (Social } \\
\text { Context) }\end{array}$ \\
\hline \multirow{4}{*}{$\begin{array}{l}\text { Leighley } \\
\text { (1990) }\end{array}$} & \multirow{4}{*}{$\begin{array}{l}\text { Information/resour } \\
\text { ce requirement } \\
\text { (low to high) }\end{array}$} & Voting & + \\
\hline & & Contacting & + \\
\hline & & Campaigning & + \\
\hline & & Cooperative activities & 0 \\
\hline \multirow{2}{*}{$\begin{array}{l}\text { McLeod et al. } \\
\text { (1994) }\end{array}$} & Traditional & Voting, donating money & \\
\hline & Nontraditional & $\begin{array}{l}\text { Participating in public fora, } \\
\text { town hall meetings }\end{array}$ & + \\
\hline \multirow[t]{3}{*}{$\begin{array}{l}\text { Mutz } \\
(2002,2006)\end{array}$} & Confrontational & $\begin{array}{l}\text { Convincing other people to } \\
\text { vote for/against a candidate, } \\
\text { working for a party/candidate }\end{array}$ & - \\
\hline & Non-confrontational & $\begin{array}{l}\text { Attending meetings/rallies, } \\
\text { displaying a yard sign/sticker/ } \\
\text { button, donating money }\end{array}$ & 0 \\
\hline & Voting & Voting & - \\
\hline
\end{tabular}




\section{Conclusion}

In sum, the current research lays a basic understanding of what methodological approaches to political diversity and political participation exist in current literature. It is an attempt to find the causes of the inconsistency in the research on the relation between political diversity and political participation in the variety of methodological approaches to the two variables.

As to political participation, studies in the literature sought to identify what specific dimension of political involvement (e.g., information requirement, confrontation to other people) differentiates some political acts from others in terms of susceptibility to certain social influences. For example, some see voting as an individual act (e.g., Giles \& Dantico, 1982; Huckfeldt, 1979). While others argue that voting is a product of a systemic and political process that could be affected by social conditions, including social networks, even though it is carried out individually in the isolation of a voting booth (Huckfeldt \& Sprague, 1995). In other words, public opinion is not merely the sum of individual opinions. Individual opinions are affected by other individual opinions as well as public opinion.

In association with political diversity, voting has been found to be positively (Leighley, 1990), negatively (Mutz, 2002; 2006) or not (Giles \& Dantico, 1982; Huckfeldt, 1979; Zipp \& Smith, 1979) related. Expanded to other empirical research on political diversity and political participation, Table 3 presents the ways in which studies dealt with voting and other political participatory behaviors. Some studies observe voting only (e.g., Jang, 2009), some exclude it (e.g., Kwak et al., 2005), some include it in a broad definition of "participation" together with other activities (e.g., Scheufele et al., 2006), and some examine it in separation from other participatory forms (e.g., Mutz, 2002). As suggested by the studies discussed thus far, political participation must be defined in the way that best captures what is under study.

Social contexts such as discussion networks play a crucial role in our political behaviors as the review of the relation of political diversity to political participation in this study has indicated. Such everyday mundane social conditions as who we meet to talk about politics (someone of a different race or whom we disagree with), how many people we discuss politics with (network size), how often we hold conversations on 
politics (discussion frequency), or whether we talk to someone close or distant (tie strength) all contribute to what political activities and how many of them we decide to engage in. Consequently, the extent to which individuals communicate and engage with one another in society affects the formation of public opinion.

None of the measures of political diversity and political participation discussed thus far can be said to be wrong. While each of them has strengths as well as weaknesses, we have the option of eclectic selection and employment of the measures to serve the purpose of a proposed public opinion study. What is important then is to ensure that the conceptualization and operationalization of the selected measures meet the focus of the study. In order to do so, it appears to be imperative that we fully understand why we choose one measurement approach and not others. 


\begin{tabular}{|c|c|c|c|c|c|}
\hline & 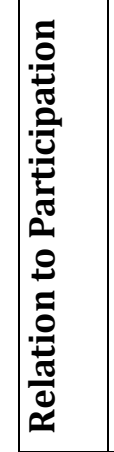 & 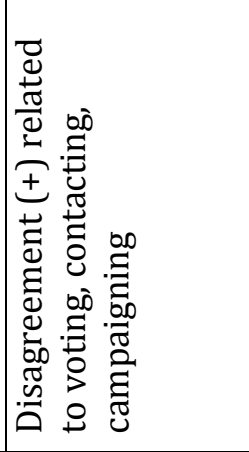 & 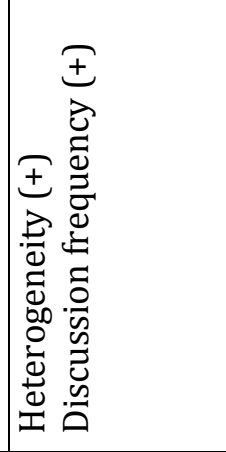 & 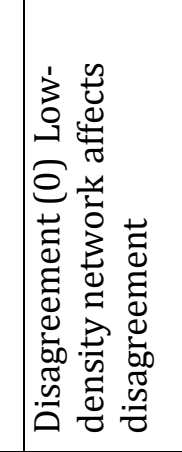 & 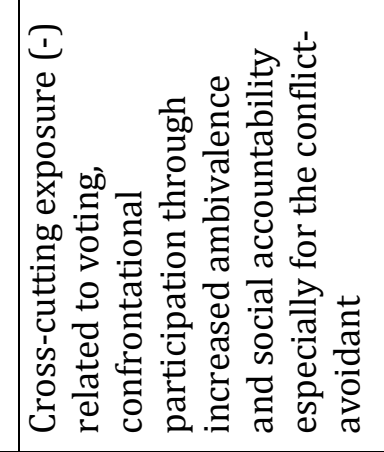 \\
\hline$\tilde{\bar{\Xi}}$ & 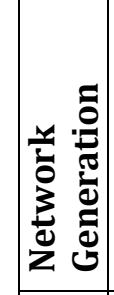 & 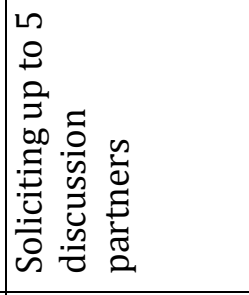 & 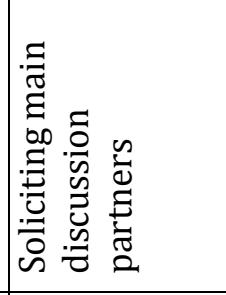 & 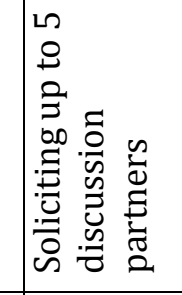 & 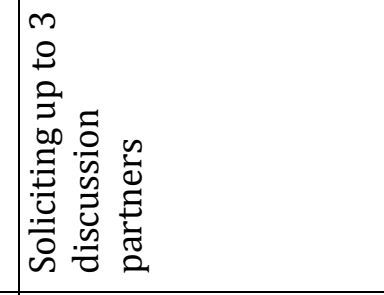 \\
\hline 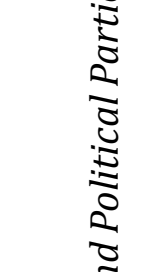 & 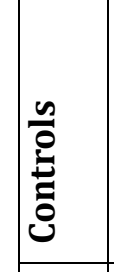 & 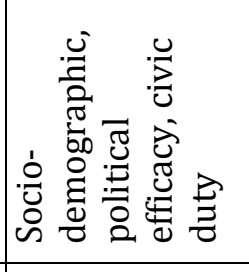 & 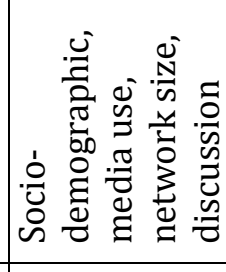 & 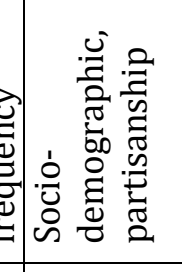 & 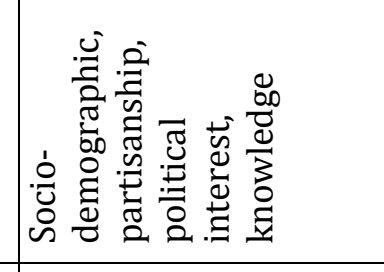 \\
\hline 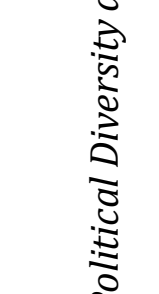 & 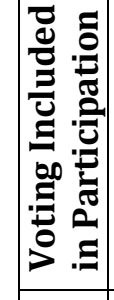 & 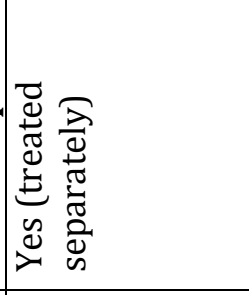 & $\not$ & 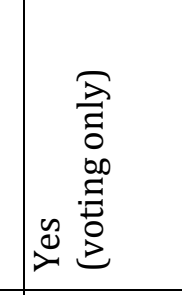 & 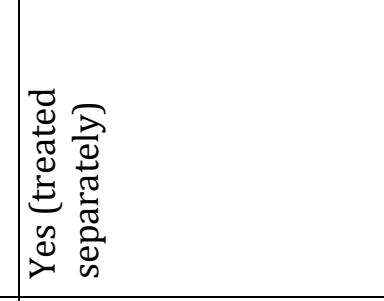 \\
\hline 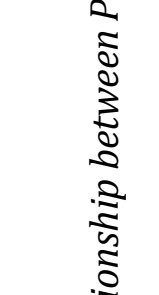 & 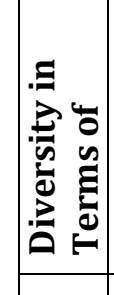 & 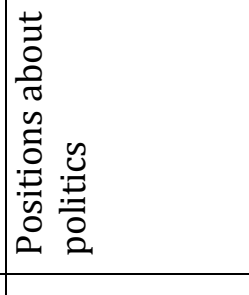 & 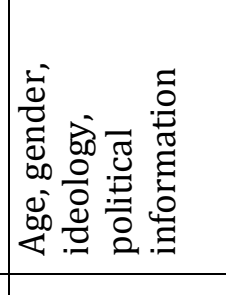 & 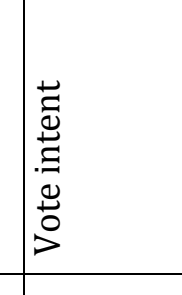 & 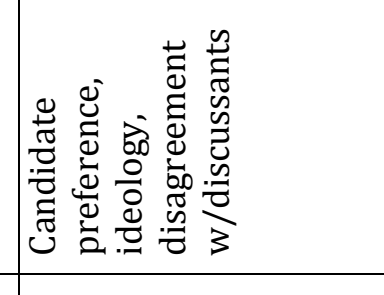 \\
\hline 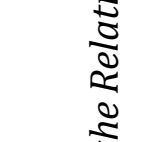 & $\mid$ & & $\underset{7}{0}$ & 党 & $\stackrel{\infty}{\infty}$ \\
\hline $\begin{array}{l}\tilde{\delta} \\
\tilde{0} \\
\tilde{\tilde{z}}\end{array}$ & 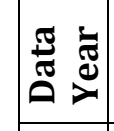 & $\begin{array}{l}0 \\
2 \\
2 \\
\end{array}$ & 余 & $\begin{array}{l}\hat{\alpha} \\
\text { बे }\end{array}$ & 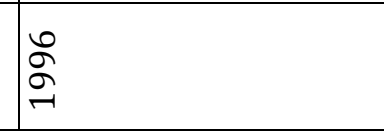 \\
\hline 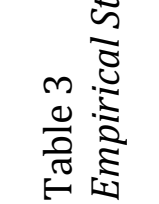 & 产 & 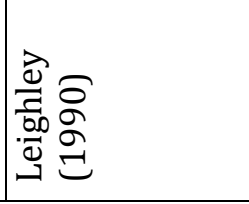 & 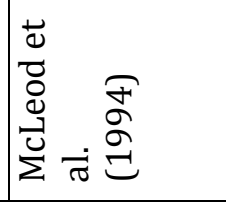 & 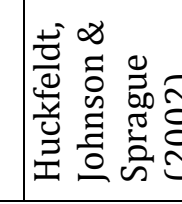 & is \\
\hline
\end{tabular}




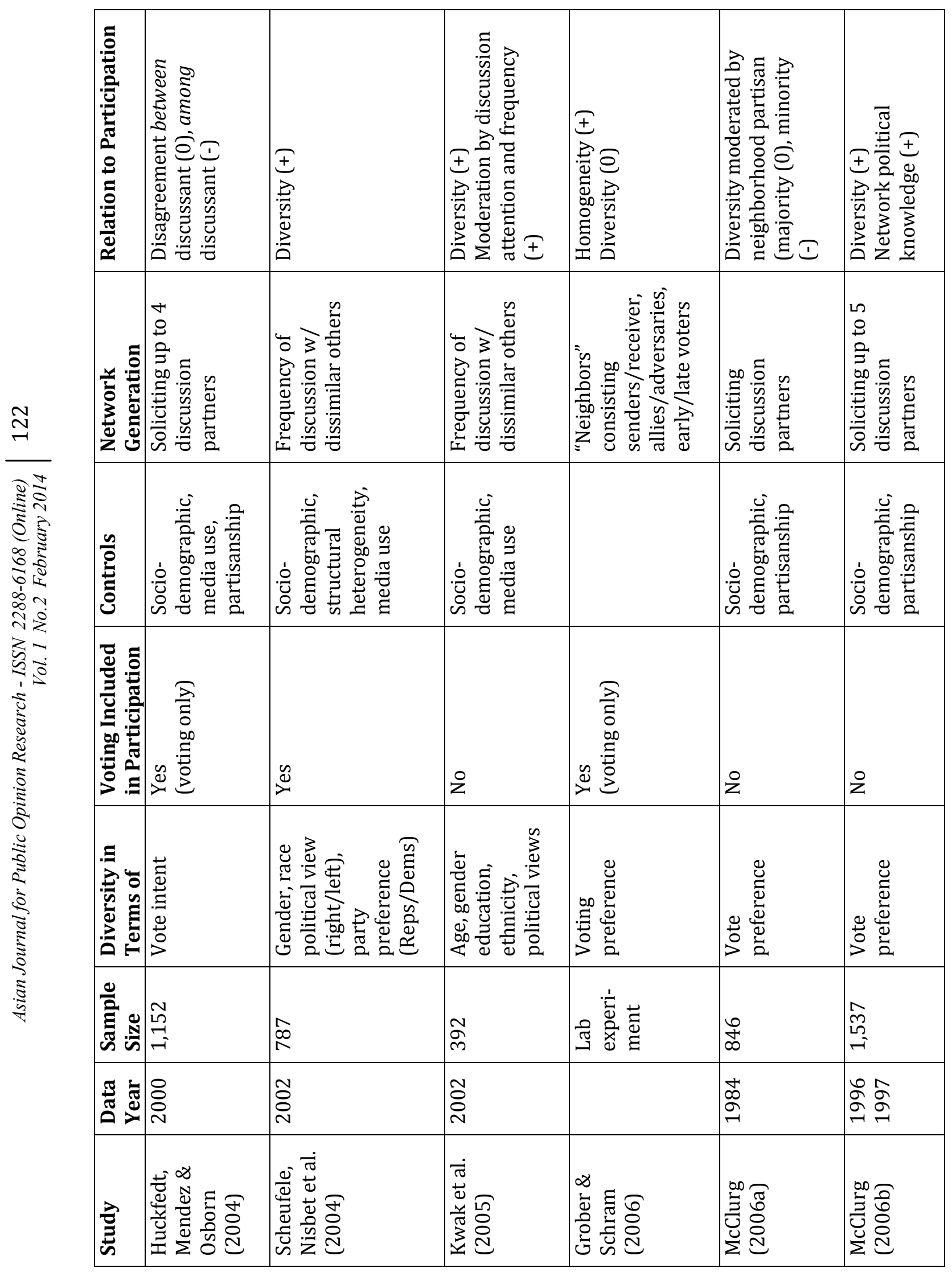




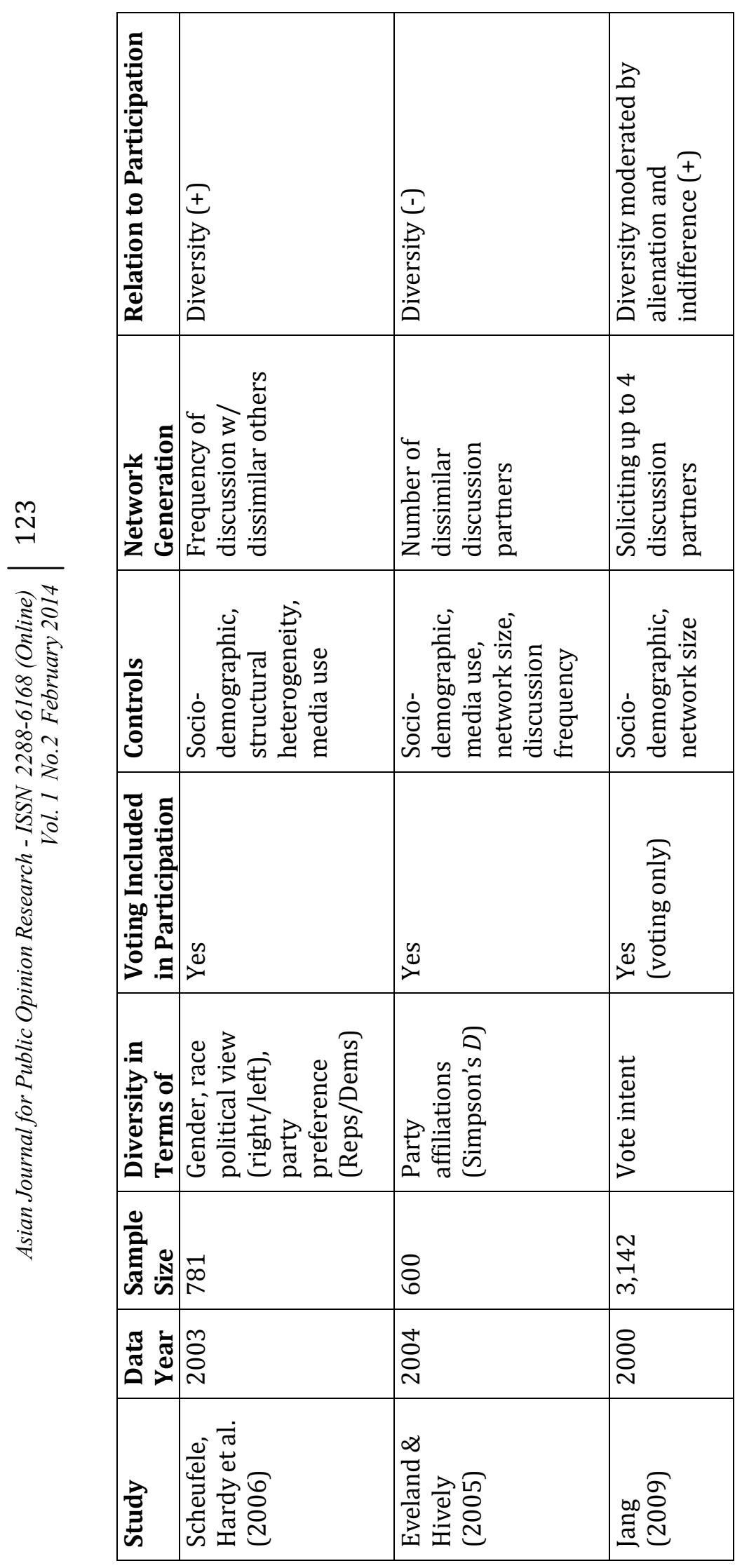




\section{References}

Berelson, B., Lazarsfeld, P., \& McPhee, W. (1954). Voting: A Study of Opinion Formation in a Presidential Campaign. Chicago: University of Chicago Press.

Berger, C. R. (2009). Interpersonal communication. In D. W. Stacks \& M. B. Salwen (Eds.), Civic Life Online: Learning How Digital Media Can Engage Youth (pp. 1-24). Cambridge, MA: MIT Press.

Brundidge, J. (2010). Encountering "difference" in the contemporary public sphere: The contribution of the Internet to the heterogeneity of political discussion networks. Journal of Communication, 60(4), 680-700.

Burt, R. S. (1992). Structural Holes: The Social Structure of Competition. Cambridge, MA: Harvard University Press.

Cambell, A., Gurin, G., \& Miller, W. E. (1954). The Voter Decides. Evanston, IL: Row, Peterson.

Eveland, W. P., Jr., \& Hively, M. H. (2005). Political discussion frequency, network size and "heterogeneity" of discussion as predictors of political knowledge and participation. Journal of Communication, 59(2), 205-224.

Garrett, R. K. (2009). Echo chambers online?: Politically motivated selective exposure among Internet news users. Journal of Computer Mediated Communication, 14(2), 265285.

Gil de Zúñiga, H., \& Valenzuela, S. (2011). The mediating path to a stronger citizenship: Online and offline networks, weak ties, and civic engagement. Communication Research, 38(3), 387-421.

Giles, M. W., \& Dantico, M. K. (1982). Political participation and the neighborhood social context revisited. American Journal of Political Science, 26(1), 144-50.

Granovetter, M. (1973). The strength of weak ties. American Journal of Sociology, 78(6), 1360-1380.

Großer, J., \& Schram, A. (2006). Neighborhood information exchange and voter participation: An experimental study. American Political Science Review, 100(2), 235248.

Huckfeldt, R. (1979). Political participation and the neighborhood social context. American Journal of Political Science. 23(3), 579-92. 
Huckfeldt, R., Johnson, P. E., \& Sprague, J. (2002). Political environments, political dynamics, and the survival of disagreement. The Journal of Politics, 64(1), 1-21.

Huckfeldt, R., Johnson, P. E., \& Sprague, J. (2004). Political Disagreement: The Survival of Diverse Opinions within Communication Networks. New York: Cambridge University.

Huckfeldt, R., Mendez, J. M. and Osborn, T. (2004). Disagreement, Ambivalence, and Engagement: The Political Consequences of Heterogeneous Networks. Political Psychology, 25(1), 65-95.

Huckfeldt, R., \& Sprague, J. (1995). Citizens, Politics, and Social Communication: Information and Influence in an Election Campaign. New York: Cambridge University Press.

Jang, S. (2009). Are diverse political networks always bad for participatory democracy? Indifference, alienation, and political disagreements. American Politics Research, 37(5), 879-898.

Jun, N. (2012). Contribution of Internet news use to reducing the influence of selective online exposure on political diversity. Computers in Human Behavior, 28(4), 1450-1457.

Katz, E., \& Lazarsfeld, P. F. (1955). Personal Influence: The Part Played by People in the Flow of Mass Communication. Glencoe, IL: Free Press.

Kenny, C. B. (1994). The microenvironment of attitude change. Journal of Politics. 56(3), 715-728.

Kwak, N., Willams, A. E., Wang, X., \& Lee, H. (2005). Talking politics and engaging politics: An examination of the interactive relations between structural features of political talk and discussion engagement. Communication Research. 32(1), 87-111.

Lazarsfeld, P., Berelson, B., \& Gaudet, H. (1944). People's Choice: How the Voter Makes Up His Mind in a Presidential Campaign. New York: Duell, Sloan \& Pearce.

Leighley, J. (1990). Social interaction and contextual influences on political participation. American Politics Research, 18(4), 459-475.

Lin, N. (2001) Social Capital: A Theory of Social Structure and Action. Cambridge: Cambridge University Press.

McClurg, S. D. (2006a). Political disagreement in context: The conditional effect of neighborhood context, disagreement and political talk on electoral participation. Political Behavior. 28(4), 349-366. 
McClurg, S. D. (2006b). The electoral relevance of political talk: Examining disagreement and expertise effects in social networks on political participation. American Journal of Political Science, 50(3), 737-754.

McLeod, J. M., Kosicki, G. M., \& McLeod, D. M. (1994). The expanding boundaries of political communication effects. In J. Bryant \& D. Zillmann (Eds.), Media effects: Advances in theory and research (pp. 123-162). Hillsdale, NJ: Lawrence Erlbaum.

McPherson, M., Smith-Lovin, L., \& Cook J. M. (2001). Birds of a feather: Homophily in social networks. Annual Review of Sociology, 27, 415-444.

Moy, P., \& Gastil, J. (2006). Predicting deliberative conversation: The impact of discussion networks, media use, and political cognitions. Political Communication, 23(4), 443-460.

Mutz, D. C. (2002). The consequences of cross-cutting networks for political participation. American Journal of Political Science, 46(4), 838-855.

Mutz, D. C. (2006). Hearing the other side: deliberative versus participatory democracy. New York: Cambridge University.

Mutz, D. C., \& Martin, P. S. (2001). Facilitating communication across lines of political difference. The American Political Science Review, 95(1), 97-114.

Orum, A. M. (1976). Individual autonomy and social constraints in the political arena: Signs and designs in the United States. Paper presented at the annual meeting of the Society for the Study of Social Problems, New York City.

Scheufele, D. A., Hardy, B.W., Brossard, D., Waismel-Manor, I. S., \& Nisbet, E. C. (2006). Democracy based on difference: Examining the links between structural heterogeneity, heterogeneity of discussion networks, and democratic citizenship. Journal of Communication, 56(4), 728-753.

Scheufele, D. A., Nisbet, M. C., Brossard, D., \& Nisbet, E. C. (2004). Social structure and citizenship: Examining the impact of social setting, network heterogeneity, and informational variables on political participation. Political Communication, 21(3), 315338.

Schmitt-Beck, R. (2004). Political communication effects: The impact of mass media and personal conversations on voting. In E. Esser, \& B. Pfetsch (Eds.), Comparing Political communication: Theories, Cases and Challenges (pp. 293-322). Cambridge, UK: Cambridge University Press.

Son, J., \& Lin, N. (2008). Social capital and civic action: A network-based approach. Social Science Research, 37(1), 330-349. 
Stroud, N. J. (2007). Media use and political predispositions: Revisiting the concept of selective exposure. Political Behavior. 30(3), 341-366.

Ulbig, S. G., \& Funk, C. L. (1999). Conflict avoidance and political participation. Political Behavior, 21(3), 265-282.

Verva, S., Schlozman, K. L., \& Brady, H. E. (1995). Voice and Equality: Civic Voluntarism in American Politics. Cambridge, MA: Harvard University Press.

Weismann, G. (1982). On the importance of marginality: One more step into the two-step flow of communication. American Sociological Review, 47(6), 764-773.

Zipp, J. F., \& Smith, J. (1979). The structure of electoral political participation. American Journal of Sociology. 85(1), 167-77.

\section{Biographical Notes}

Dr. Najin Jun is Assistant Professor in the Department of Global Communication \& Culture at Hannam University, Korea. She teaches courses in communication theory, media studies and political communication. Her research interests include political diversity, political tolerance and new media. She was educated in Korea, India, Singapore and the United States, and has traveled extensively.

She can be reached at njun@hannam.ac.kr.

Date of the submission: $2014-01-29$

Date of the review result: 2014-02-09

Date of the decision: 2014-02-14 